\title{
Correlation between Slug transcription factor and miR-221 in MDA-MB-231 breast cancer cells
}

\author{
Elisabetta Lambertini ${ }^{1}$, Andrea Lolli ${ }^{1}$, Federica Vezzali ${ }^{1}$, Letizia Penolazzi ${ }^{1}$, Roberto Gambari ${ }^{2}$ and Roberta Piva ${ }^{1 *}$
}

\begin{abstract}
Background: Breast cancer and its metastatic progression is mainly directed by epithelial to mesenchymal transition (EMT), a phenomenon supported by specific transcription factors and miRNAs.

Methods: In order to investigate a possible correlation between Slug transcription factor and miR-221, we performed Slug gene silencing in MDA-MB-231 breast cancer cells and evaluated the expression of genes involved in supporting the breast cancer phenotype, using qRT-PCR and Western blot analysis. Chromatin immunoprecipitation and wound healing assays were employed to determine a functional link between these two molecules.

Results: We showed that Slug silencing significantly decreased the level of miR-221 and vimentin, reactivated Estrogen Receptor $a$ and increased E-cadherin and TRPS1 expression. We demonstrated that miR-221 is a Slug target gene, and identified a specific region of miR-221 promoter that is transcriptionally active and binds the transcription factor Slug "in vivo". In addition, we showed that in Slug-silenced cells, wich retained residual miR-221 (about 38\%), cell migration was strongly inhibited. Cell migration was inhibited, but to a less degree, following complete knockdown of miR-221 expression by transfection with antagomiR-221.

Conclusions: We report for the first time evidence of a correlation between Slug transcription factor and miR-221 in breast cancer cells. These studies suggest that miR-221 expression is, in part, dependent on Slug in breast cancer cells, and that Slug plays a more important role than miR-221 in cell migration and invasion.
\end{abstract}

Keywords: Slug, miR-221, Epithelial mesenchymal transition, Breast cancer

\section{Background}

Epithelial cancers such as breast carcinomas and their metastatic progression are mainly directed by a phenomenon referred to as epithelial to mesenchymal transition (EMT) $[1,2]$. As well described in several reviews, EMT is supported by the same transcription factors (TFs) including ZEB factors and the Snail family of zinc finger proteins both during embryonic development and the metastatic cascade [1,3-5]. In addition, specific microRNAs (miRNAs) including miR-206, miR-221/222, miR-200, miR-141, miR-203, miR-130a, have been shown to regulate EMT [6-11].

Mounting evidence indicates that the acquisition of an aggressive cancer phenotype through EMT, as well as other cellular events, may be understood by evaluating the regulatory interplay between TFs and miRNAs $[12,13]$.

\footnotetext{
* Correspondence: piv@unife.it

${ }^{1}$ Department of Biomedical and Specialty Surgical Sciences, University of Ferrara, Ferrara 44121, Italy

Full list of author information is available at the end of the article
}

Therefore, recent studies have investigated the interactions among specific miRNAs, TFs and target genes associated with this phenomenon. Direct evidence of these circuits in EMT is still little. Some specific networks have been described including miR-203 - Snail [14], a selfreinforcing loop miR-1/miR-200 via Slug [15], miR-200/ miR-192 - p53 [16], miR-221/222 - TRPS1 [17], p53/ miR-34 axis [18], and ZEB/miR-200 [19].

To investigate the key regulatory networks underlying EMT in breast cancer, we evaluated a potential correlation between Slug (SNAI2) transcription factor and miR-221. The ability of miR-221 and Slug to promote EMT and induce invasiveness in breast cancer cell lines has been documented, but crosstalk between these molecules has not been characterized $[3,17,20]$.

Slug is a member of the Snail family of zinc-finger transcription factors, and, together with Snail (SNAI1), acts as a master regulator of EMT. Various studies over

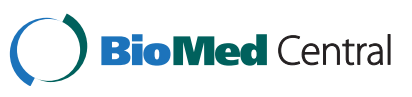


the past several years have documented the involvement of Slug in human cancers including leukemias [21], osteosarcoma [22], esophageal carcinomas [23], and breast cancers $[3,24]$, where Slug expression is strongly correlated with the loss of E-cadherin. Multiple lines of evidence suggest that Slug can be considered a marker of malignancy as well as an attractive target for therapeutic modulation of invasiveness in the treatment of specific cancers [25-28].

miR-221 is often overexpressed in aggressive cancers, increases cell proliferation and protects cancer cells against different apoptotic stimuli [29-31]. Recently, the expression level of miR-221 has been significantly associated with Estrogen Receptor alpha $(E R \alpha)$ status in breast cancer, and several studies have demonstrated that miR-221 directly targets ER $\alpha[9,32,33]$. Breast tumors from patients with high miR-221 plasma levels tend to be ER $\alpha$-negative, more aggressive and show poorer clinical outcomes than ER $\alpha$ positive cancers [34]. In addition, ER $\alpha$ signaling has been correlated with Slug, and at least two different mechanisms showed that ER $\alpha$ decreases Slug expression [35-37].

In this study, we knocked down Slug and miR-221 in ER $\alpha$-negative breast cancer cells, MDA-MB-231. We determined a functional correlation between these two molecules demonstrating "in vivo" interaction between Slug and miR-221. Rescue experiments with ectopic expression of miR-221, analysis of the expression of genes involved in breast cancer phenotype, and wound healing assay, suggested that the largest contribution to the invasion ability of the cells and their aggressive phenotype comes from Slug rather than miR-221.

\section{Methods}

\section{Cell culture}

Human breast cancer cell lines MDA-MB-231 and MDAMB-436 were cultured in Dulbecco's modified Eagle medium-High Glucose (DMEM-HG) (Euroclone S.p.a., Milan, Italy), supplemented with $10 \%$ Fetal Calf Serum (FCS) (Euroclone), $2 \mathrm{mM} \mathrm{L-glutamine} \mathrm{and} 100 \mathrm{U} / \mathrm{ml}$ penicillin-streptomycin.

\section{Transfections}

Breast cancer cells were transfected with $30 \mathrm{nM}$ siRNA against Slug (Invitrogen, Carlsbad, CA) [38], $30 \mathrm{nM}$ antagomiR-221, $50 \mathrm{nM}$ pre-miR-221 precursor (named miR-221 mimic) (Ambion Life Technologies, Grand Island, NY), a non-relevant siRNA (si-Scr) (Medium GC Stealth RNAi Negative Control Duplex, Invitrogen), a non-relevant (miR-Scr) mimic and a non-relevant antagomiR (antagomiR-Scr) (Ambion Life Technologies, Grand Island, NY). For all transfections Lipofectamine RNAiMAX (Invitrogen) was used, following the manufacturer's instructions. In brief, cells were plated the day before transfections in 12-well plates. Transfected cells were grown up to 6 days in a $37^{\circ} \mathrm{C}$ incubator with $5 \% \mathrm{CO}_{2}$. Total RNA and proteins were extracted, and stored at $-80^{\circ} \mathrm{C}$ for subsequent quantitative RT-PCR or Western Blot measurements. Each treatment used at least triplicate samples.

\section{RNA extraction}

Total RNA including miRs was extracted from breast cancer cell lines using an RNeasy Mini Kit (Qiagen, Hilden, Germany) according to the manufacturer's instruction and as previously described [39]. Total RNA was used for reverse-transcription and stored at $-80^{\circ} \mathrm{C}$. Briefly, cDNA was synthesized from total RNA (500 ng) in a $10 \mu \mathrm{l}$ reaction volume using the TaqMan MicroRNA Reverse Transcription Kit (Applied Biosystems). The reactions were incubated first at $16^{\circ} \mathrm{C}$ for $30 \mathrm{~min}$ and then at $42^{\circ} \mathrm{C}$ for $30 \mathrm{~min}$ followed by inactivation at $85^{\circ} \mathrm{C}$ for $5 \mathrm{~min}$.

\section{Quantitative real-time PCR for miRNA and mRNA quantification}

Quantification of miR-221 and miR-222 was performed using TaqMan MicroRNA Assays (Applied Biosystems), followed by detection with the CFX96 ${ }^{\mathrm{TM}}$ PCR detection system (Bio-Rad, Hercules, CA). The TaqMan MicroRNA Assay for U6 snRNA (assay ID: 001973; Applied Biosystems) was used to normalize the relative abundance of miR-221 and miR-222. For quantification of Slug, E-cadherin, ER $\alpha$ and TRPS1 mRNAs and primiR-221 the appropriate TaqMan probes were purchased from Applied Biosystems using GAPDH reference gene for normalization. Relative expression was calculated using the comparative $\Delta \Delta C T$ method and the change in miRNA or mRNA expression was calculated as fold-change. All reactions were performed in triplicate. The experiment was repeated at least three times.

\section{Western blotting}

For western blot analysis, the cells were washed twice with ice-cold PBS and cell lysates were prepared as previously reported [39]. Then, $20 \mu \mathrm{g}$ of each sample were electrophoresed on a $12 \%$ SDS-polyacrylamide gel. The proteins were then transferred onto an Immobilon-P PVDF membrane (Millipore, Billerica, MA). After blocking with PBS-0.05\% Tween 20 and 5\% dried milk, the membrane was probed with the following antibodies: Slug (L40C6) from Cells Signaling Technology (Danvers, CA, USA), ER $\alpha$ (sc-544), E-cadherin (sc-7870), Vimentin (sc-7558) and p53 (sc-126) from Santa Cruz Biotechnology (Santa Cruz, CA). After washing with PBS-Tween, the membranes were incubated with peroxidase-conjugated anti-rabbit antibody (1:50000) or anti-mouse (1:2000) (Dako, Glostrup, Denmark) in 5\% non-fat milk. Immunocomplexes 
were detected using Supersignal West Femto Substrate (Pierce, Rockford, IL). Anti-IP3K was used to confirm equal protein loading.

\section{Viability analysis (calcein-AM uptake assay)}

Viability assay was performed as described previously [40]. For propidium iodide and calcein analysis the cells were visualized under a fluorescence microscope (Nikon, Optiphot-2, Nikon corporation, Japan) using the filter block for fluorescein. Dead cells were stained in red, whereas viable ones appeared in green.

\section{Cell cycle analysis}

Cell cycle analysis was performed using fluorescenceactivated cell sorting (FACS). Briefly, MDA-MB-231 cells were collected 72 hours after transfection and stained with $25 \mu \mathrm{g} / \mathrm{mL}$ of propidium iodide (Roche Molecular Biochemicals, Indianapolis, IN) in phosphate-buffered saline containing $0.1 \%$ bovine serum albumin, $0.05 \%$ of Triton X-100, and $50 \mu \mathrm{g} / \mathrm{mL}$ of RNase A. Analysis were carried out using FACS Scan (Becton Dickinson, NJ).

\section{Cell proliferation assay}

For growth curves analysis an equal number of cells (approximately $3 \times 10^{4}$ ) were seeded into 24-well plates. Twenty-four hours after transfection, the cells were harvested and counted by trypan blue exclusion method every day up to three days and at day 6 .

\section{Scratch wound assay}

Forty-eight-hours after transfection a vertical wound was created in the MDA-MB-231 cell layer using a $20-\mu \mathrm{L}$ pipette tip. Images were captured at designated times ( 0 and 24 hours) to assess the rate of gap closure.

\section{Chromatin immunoprecipitation (ChIP) assay}

Chromatin immunoprecipitation (ChIP) assays were performed with the ChIP assay kit (Upstate Biotechnology, Lake Placid, NY) as previously described [38]. Briefly, MDA-MB-231 cells were grown to $70 \%$ confluency in DMEM supplemented with 10\% FBS. Cross-linking was performed with $1 \%$ formaldehyde at $37^{\circ} \mathrm{C}$ for $10 \mathrm{~min}$, the cells were washed in ice-cold PBS, and suspended in SDS lysis buffer supplemented with $1 \times$ protease inhibitor cocktail (Roche Molecular Biochemicals), for $10 \mathrm{~min}$ on ice. Samples were sonicated, diluted 10-fold in dilution buffer, and precleared with $80 \mu \mathrm{l}$ of salmon sperm DNA-coated protein A-agarose beads; the supernatant was used directly for immunoprecipitation with antiSlug, (sc-10436), anti-acetyl-H3 (sc-56616) or rabbit Ig $\lambda$ chain control antibody (sc-33134) (Santa Cruz Biotechnology, INC) overnight at $4^{\circ} \mathrm{C}$. Immunocomplexes were mixed with $80 \mu \mathrm{l}$ of DNA-coated protein A-agarose beads followed by incubation for $1 \mathrm{~h}$ at $4^{\circ} \mathrm{C}$. Beads were collected and sequentially washed 3 times with $1 \mathrm{ml}$ each of the following buffers: low salt wash buffer $(0.1 \%$ SDS, 1\% Triton X-100, 2 mM EDTA, 20 mM Tris-HCl $\mathrm{pH} 8.1,150 \mathrm{mM} \mathrm{NaCl})$, high salt wash buffer (0.1\% SDS, 1\% Triton X-100, 2 mM EDTA, 20 mM Tris-HCl pH-8.1, $500 \mathrm{mM} \mathrm{NaCl}), \mathrm{LiCl}$ wash buffer $(0.25 \mathrm{mM} \mathrm{LiCl}, 1 \%$ IGEPAL-CA630, 1\% deoxycholic acid, $1 \mathrm{mM}$ EDTA, $10 \mathrm{mM}$ Tris-pH 8.1), and TE buffer. The immunocomplexes were eluted twice by adding a $250 \mu \mathrm{l}$ aliquot of a freshly prepared solution of $1 \%$ SDS, $0.1 \mathrm{M} \mathrm{NaHCO}_{3}$ and the cross-linking reactions were reversed by incubation at $65^{\circ} \mathrm{C}$ for $4 \mathrm{hrs}$. Further, the samples were digested with proteinase $\mathrm{K}(10 \mathrm{mg} / \mathrm{ml})$ at $42^{\circ} \mathrm{C}$ for 1 hour and DNA was purified in $50 \mu \mathrm{L}$ of Tris-EDTA with a PCR purification kit (Qiagen, Valencia, CA) according to the manufacturer's instructions. For PCR analysis, aliquots of chromatin before immunoprecipitation were saved (Input). PCR was performed to analyze the presence of DNA precipitated by Slugspecific antibody, and by using specific primers to amplify fragments of the miR-221 and TRPS1 gene promoters. Each PCR reaction was performed with 5 $\mu \mathrm{l}$ of the bound DNA fraction or $2 \mu$ l of the Input. The PCR was performed as follows: preincubation at $95^{\circ} \mathrm{C}$ for $5 \mathrm{~min}, 30$ cycles of $1 \mathrm{~min}$ denaturation at $95^{\circ} \mathrm{C}, 1 \mathrm{~min}$ annealing at the primers temperature, and $1 \mathrm{~min}$ at $72^{\circ} \mathrm{C}$, with one final incubation at $72^{\circ} \mathrm{C}$ for $5 \mathrm{~min}$. No-antibody negative control was included in each experiment.

\section{Statistical analysis}

Data are presented as means \pm SEM. For qRT-PCR and cell cycle analysis assays, statistical significance was analyzed by unpaired Student's t test. p-values $\leq 0.05$ were considered statistically significant.

\section{Results and discussion}

\section{Correlation between Slug and miR-221 expression}

The ability of miR-221 and Slug to promote EMT in breast cancer cell lines, led us to investigate a potential correlation between these molecules. Consistent with previous observations, we confirmed that miR-221 and Slug are highly expressed in breast cancer cells such as MDA-MB-231 cell line (Figure 1A and B), and are associated with an aggressive phenotype. However, as demonstrated by time course experiments, miR-221 progressively decreases as cell culture proceeds (Figure 1B). This is not surprising since a large number of miRNAs shows distinct expression patterns that are often fluctuating as a consequence of their multi-functional roles $[41,42]$. Nevertheless, it is important to underline that although evidence of a role for miRNAs in cell differentiation is growing, the role of miRNAs in cell proliferation remains largely unexplored. For what concerns the expression of Slug, whose field of activity is more limited 

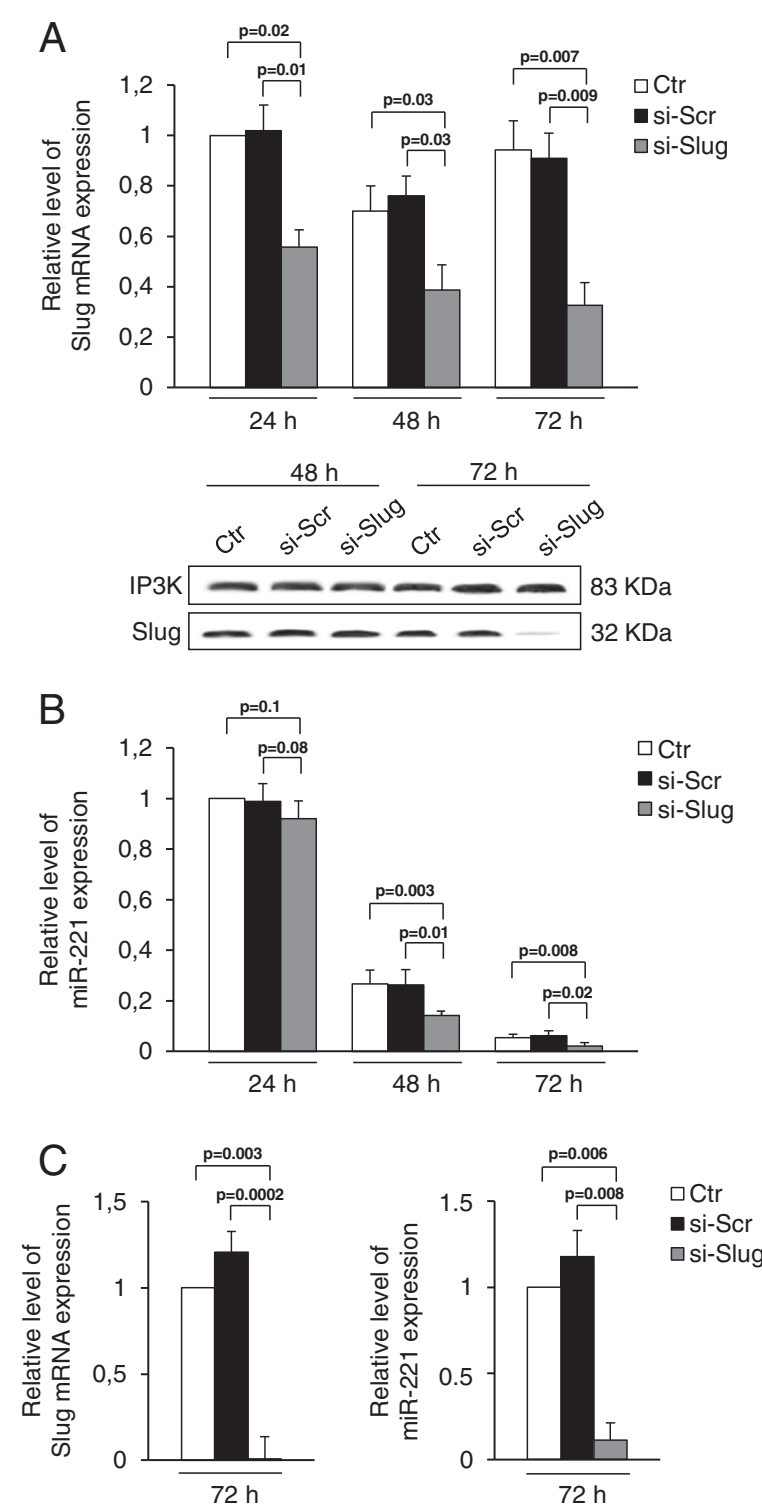

Figure 1 Effect of Slug knockdown on miR-221 expression in breast cancer cells. MDA-MB-231 (A, B) and MDA-MB-436 (C) breast cancer cells were transfected with 30nM si-Slug molecule or a non-relevant siRNA (si-Scr). Slug and miR-221 expression was determined at RNA level at three different times ( 24 h, 48 h, 72 h), and revealed by quantitative RT-PCR analysis. RT-PCR results were calculated using the $\Delta \Delta \mathrm{Ct}$ method and data are presented as fold change respect to control untreated cells ( $\mathrm{Ctr} 24 \mathrm{~h}$ for MDA-MB-231, and $\mathrm{Ctr} 72 \mathrm{~h}$ for MDA-MB-436). Results represent means \pm SEM of three independent experiments. p-values $\leq 0.05$ were considered statistically significant. In panel A, Slug expression investigated at protein level and revealed by Western Blot, is reported. IP3K was used as loading control.

with respect to miR-221, its levels were unchanged during the culture period. We then examined the effect of Slug knockdown on miR-221 expression. The efficiency of small interfering RNA targeting Slug (si-Slug), was confirmed by qRT-PCR and Western blot. As shown in
Figure 1A, Slug mRNA levels appreciably decreased after 24 hours, and Slug protein was almost completely abolished after 72 hours. Interestingly, si-Slug, but not a scrambled siRNA, significantly decreased miR-221 expression by $6 \%$ Figure $1 \mathrm{~B}$. In another $\mathrm{ER} \alpha$-negative breast cancer cell line, MDA-MB-436, Slug knockdown has the same effects (Figure 1C), strengthening the hypothesis that the presence of Slug is required for miR-221 expression. As the expression of these two molecules seems to be particularly correlated with the aggressive phenotype, we focused on MDA-MB-231 that are tumorigenic and highly metastatic compared to MDA-MB-436 that are non-tumorigenic and moderately metastatic $[43,44]$.

The effect of Slug silencing and the resulting decrease of miR-221 levels was evaluated on cell growth and viability using a Calcein-AM staining and flow cytometry analysis $72 \mathrm{~h}$ after treatment. As shown in Figure 2A, the viability of cells which have been transfected with siSlug was unaffected. These data were confirmed by flow cytometry assay. No statistically significant differences in the cell percentage were detected between Slug-silenced cells and control cells in different phases of cell cycle (Figure 2B).

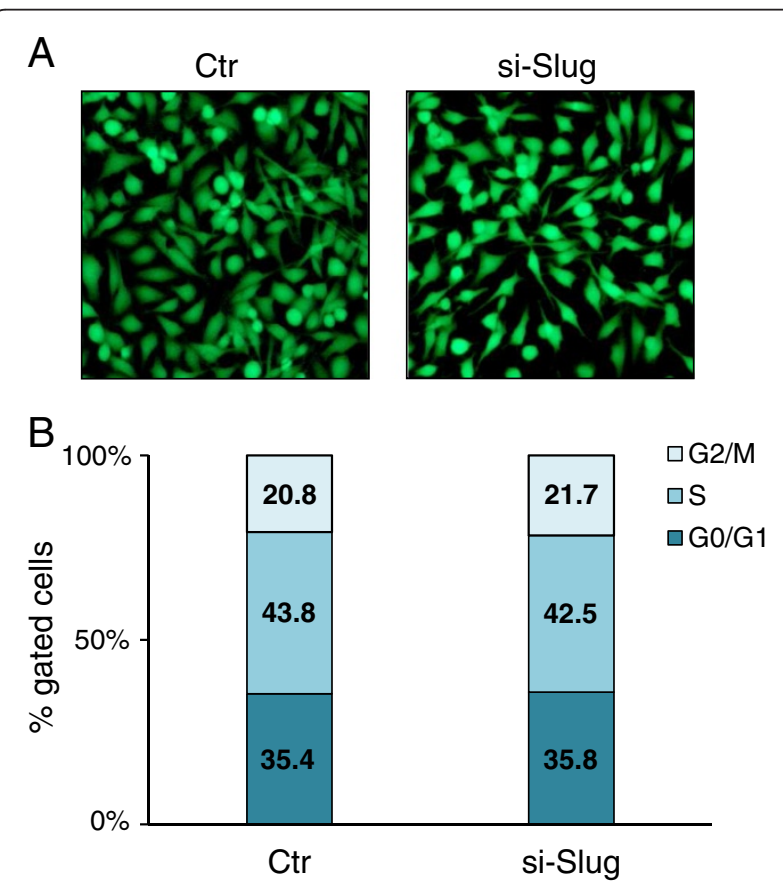

Figure 2 Effect of Slug knockdown on cell cycle and viability. MDA-MB-231 cells were transfected with si-Slug molecule and collected 72 hours after transfection. (A) Viability was determined by double staining assay with Calcein-AM and propidium iodide. Fluorescence photomicrographs (4X magnification) are representative merged images showing the presence of green fluorescence (calcein-AM)-labelled live cells and the absence of red fluorescence (PI)-labelled dead cells. (B) Cells were subjected to fluorescence-activated cell sorting analysis, and the relative G0/G1, S, and G2/M compartments calculated. Percentages of cells in each compartment are means of two independent experiments. 


\section{Recruitment of Slug at the miR-221-222 locus}

The involvement of Slug in miR-221 regulation was further investigated by chromatin immunoprecipitation (ChIP) assay. The human genomic DNA sequences belonging to the entire $5^{\prime}$ regulatory region of miR-222/221 locus have been analyzed for the presence of putative Slug binding sites (E-box motifs, 5'-CANNTG-3') [3,38], using Transcription Element Search Software (TESS) for transcription factor search and MatInspector 7.4 programs. As shown in Figure 3, five potential candidates to mediate Slug regulatory function in the miR-221 promoter are present in the region. We performed ChIP analysis to determine whether endogenous Slug transcription factor is recruited at the identified $\mathrm{E}$ boxes consensus sequences. Four chromatin sub-regions were analyzed for E-boxes occupancy by PCR revealing that region 3 was specifically involved in the interaction, whereas no chromatin was immunoprecipitated by the regions 1,2 and 4 (Figure $3 \mathrm{~A}$ ). When the ChIP assay was performed against acetylated histone 3 (Anti-AcH3), a colocalization with Slug in region 3 was detected, indicating that the identified region 3 of miR-221 promoter is transcriptionally active and is involved in the binding of transcription factor Slug. As shown in Figure 3B, following Slug silencing, the level of miR$221 / 222$ primary transcript significantly decreased (by $50 \%$ ), further demonstrating that miR-221 is a Slug target gene and is transcriptionally regulated by Slug. At the same time, the concomitant decrease of miR-222 expression levels, after Slug silencing, demonstrated that Slug is involved in the regulation of the entire miR-222/221 locus (Figure 3C).

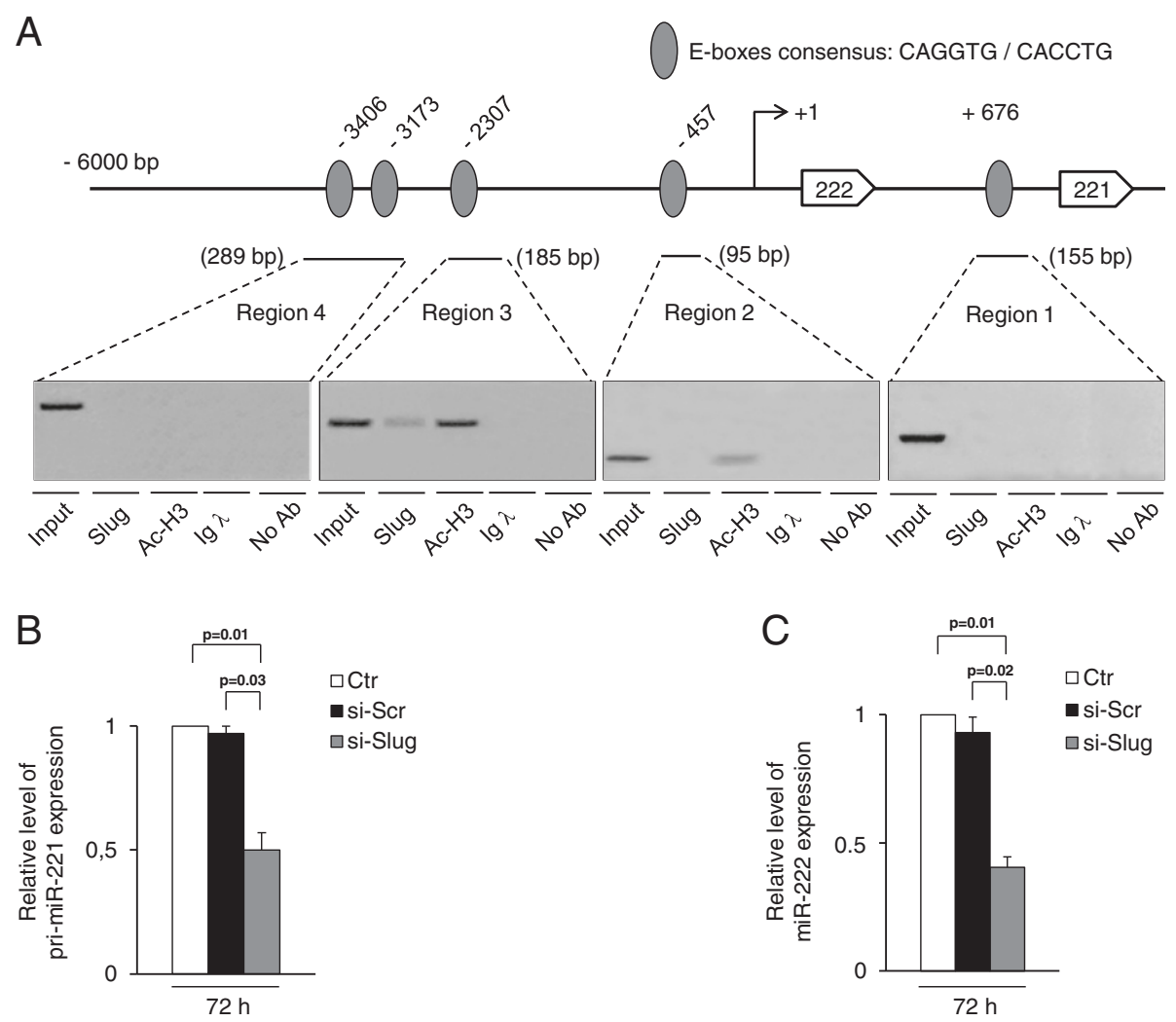

Figure 3 In vivo recruitment of Slug protein at the miR-221-222 locus. (A) The localization of predicted Slug consensus binding sites (5'-CAGGTG-3' or 5'-CACCTG-3') in the human miR-222/221 locus region is indicated with grey ovals. Protein-DNA complexes were in vivo formaldehyde-cross linked in MDA-MB-231. Chromatin fragments were subjected to immunoprecipitation with antibodies against endogenous Slug and Acetyl Histone H3 (Ac-H3). A negative control using nonspecific normal rabbit antibody against Ig $\lambda$ chain was also included. After cross-link reversal, the coimmunoprecipitated DNA was amplified by PCR using the primers pairs spanning the reported regions of miR-221 promoter (PCR amplicons are indicated by horizontal bars). Aliquots of chromatin taken before immunoprecipitation were used as Input positive controls whereas chromatin eluted from immunoprecipitation lacking antibody was used as no antibody control (No Ab). All experiments were repeated at least three times and representative images shown. MDA-MB-231 cells were transfected with 30 nM si-Slug molecule or a non-relevant siRNA (si-Scr). Pri-miR-221 (B) and miR-222 (C) expression levels were determined at RNA level after $72 \mathrm{~h}$ of treatment, and revealed by quantitative RT-PCR analysis. RT-PCR results were calculated using the $\Delta \Delta C \mathrm{Ct}$ method and data are presented as fold change respect to untreated cells (Ctr). Results represent means \pm SEM of three independent experiments. $p$-values $\leq$ 0.05 were considered statistically significant. 


\section{Effect of Slug silencing on specific gene expression}

There is evidence that many genes involved in promoting metastasis are highly expressed both in miR-221 expressing cells and in cells with high expression levels of Slug. In addition, in the same cells, the expression of many genes with a critical role in suppressing tumor growth and metastasis was found to be repressed. To further evaluate the correlation between Slug and miR-221, we analyzed the expression of some of these genes involved in supporting the breast cancer phenotype in Slug-silenced MDAMB-231 cells (Figure 4). Expression levels of E-cadherin [45], ER $\alpha$ [36], and GATA family transcriptional repressor TRPS1 (tricho-rhino-phalangeal syndrome type 1) [17], were investigated by quantitative RT-PCR (Figure 4A). $E R \alpha, p 53$, vimentin and E-cadherin expression was analyzed by Western blot (Figure 4B). Notably, si-Slug

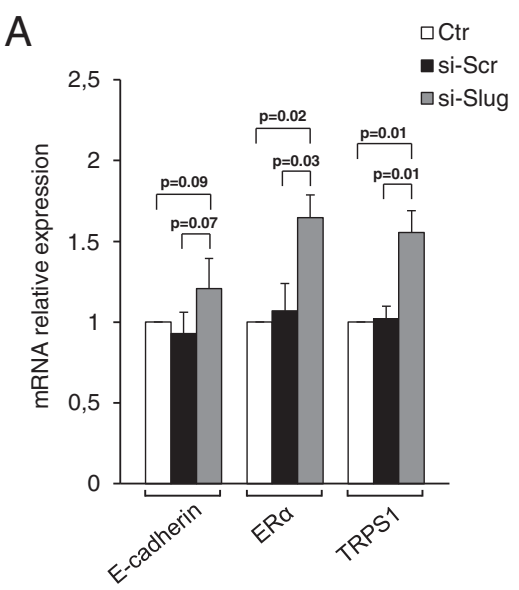

B
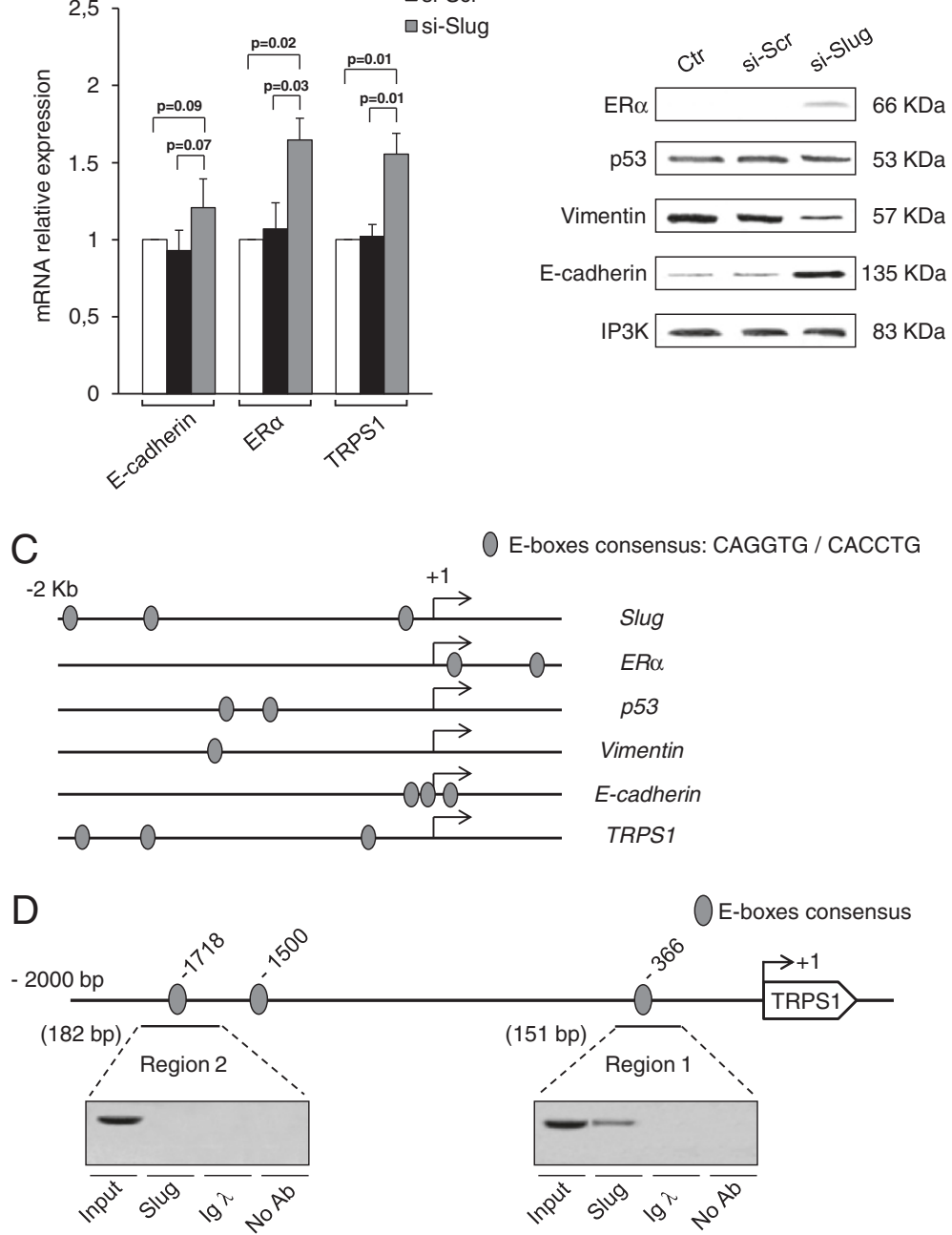

Figure 4 Effect of Slug knockdown on the expression of specific genes. MDA-MB-231 cells were transfected with si-Slug molecule or a non-relevant siRNA (si-Scr). (A) E-cadherin, ERa, TRPS1 expression was determined at mRNA level, and revealed by quantitative RT-PCR analysis. Data are represented as fold change respect to control sample (Ctr) for each gene analysed. Results represent means \pm SEM of three independent experiments. p-values $\leq 0.05$ were considered statistically significant. (B) ERa, p53, Vimentin, and E-cadherin expression was determined at protein level, and revealed by Western Blot. (C) Analysis of the $2 \mathrm{~Kb}$ in size promoter region of Slug, ERa, p53, Vimentin, E-cadherin and TRPS1 genes. Predicted E-boxes consensus-binding site are indicated with grey ovals. (D) Slug is recruited at TRPS1 promoter in vivo. The localization of predicted Slug consensus binding sites (5'-CAGGTG-3' or 5'-CACCTG-3') in the human TRPS1 promoter is reported. Protein-DNA complexes were in vivo formaldehyde-cross linked in MDA-MB-231 cells. Chromatin fragments were subjected to immunoprecipitation with antibody against endogenous Slug. A negative control using nonspecific normal rabbit antibody against lg $\lambda$ chain was also included. After cross-link reversal, the coimmunoprecipitated DNA was amplified by PCR using the primers pairs spanning the reported regions of TRPS1 promoter (PCR amplicons are indicated by horizontal bars). Aliquots of chromatin taken before immunoprecipitation were used as Input positive controls whereas chromatin eluted from immunoprecipitation lacking antibody was used as no antibody control (No Ab). All experiments were repeated at least three times and representative images shown. 
silencing reactivated $\mathrm{ER} \alpha$, increased E-cadherin and TRPS1 and decreased vimentin. On the contrary, altering Slug expression levels did not affect p53 expression. Change of gene expression was not observed in si-Scr oligomer transfected cells. These results indicate that, at the molecular level, breast cancer cells with a mesenchymal phenotype, such as MDA-MB-231, when transfected with siRNA against Slug, decrease the EMT program, reactivating an epithelial phenotype. The involvement of Slug in the regulation of ER $\alpha, \mathrm{p} 53$,

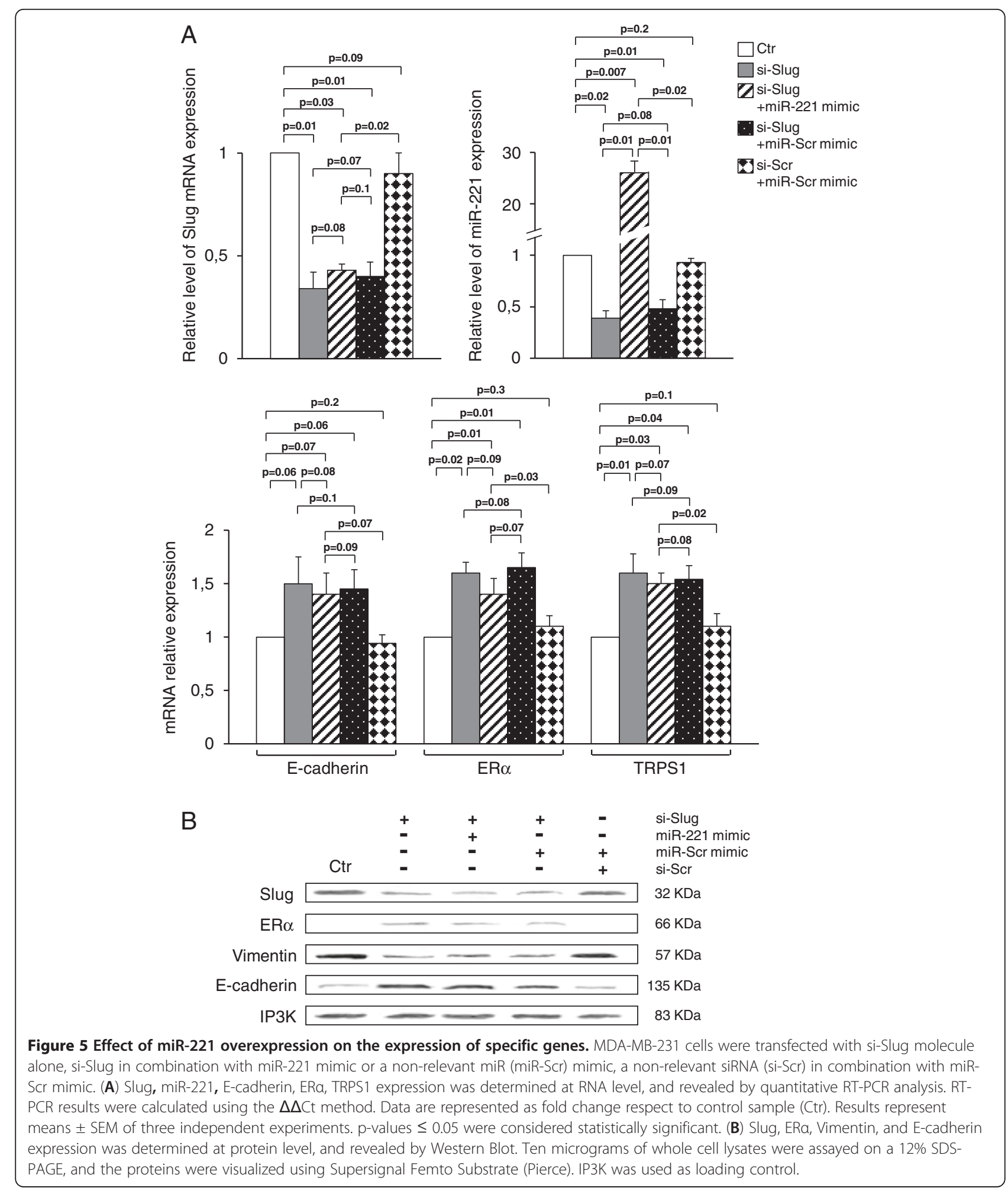


vimentin and E-cadherin, and in the activation of its own promoter by a direct binding to E-box, has been demonstrated by several lines of evidence [37,46-49]. This is confirmed by the presence of $\mathrm{E}$ boxes in the $5^{\prime}$ regulatory region of ER $\alpha$, p53, vimentin, and E-cadherin genes using TESS software (Figure 4C). The same analysis also revealed that the promoter of TRPS1 gene contains putative Slug binding sites. ChIP analysis performed on the entire sequence identified a specific involvement of region 1 , but not region 2, in the recruitment of Slug at TRPS1 promoter in vivo (Figure 4D). This suggests a direct role of Slug in the regulation of the expression of TRPS1 gene, demonstrating for the first time a link between these two molecules.
The decrease of ER $\alpha$ and TRPS1 expression is a marker of poor clinical outcome in breast cancers. Therefore, although further investigations are required to better understand the correlation among Slug, miR-221, TRPS1 and ER $\alpha$, nevertheless, removal of Slug and the consequent down-regulation of miR-221 and reactivation/ increase of ER $\alpha$ and TRPS1, may be taken into account for the treatment of ER $\alpha$-negative breast cancer.

In order to estimate the contribution of miR-221 to Slug-dependent gene regulation, Slug-silenced cells were transfected with miR-221 mimic to evaluate a possible rescue effect of miR-221 overexpression. As shown in Figure 5, the miR-221 overexpression did not restore Slug expression and did not balance si-Slug-mediated

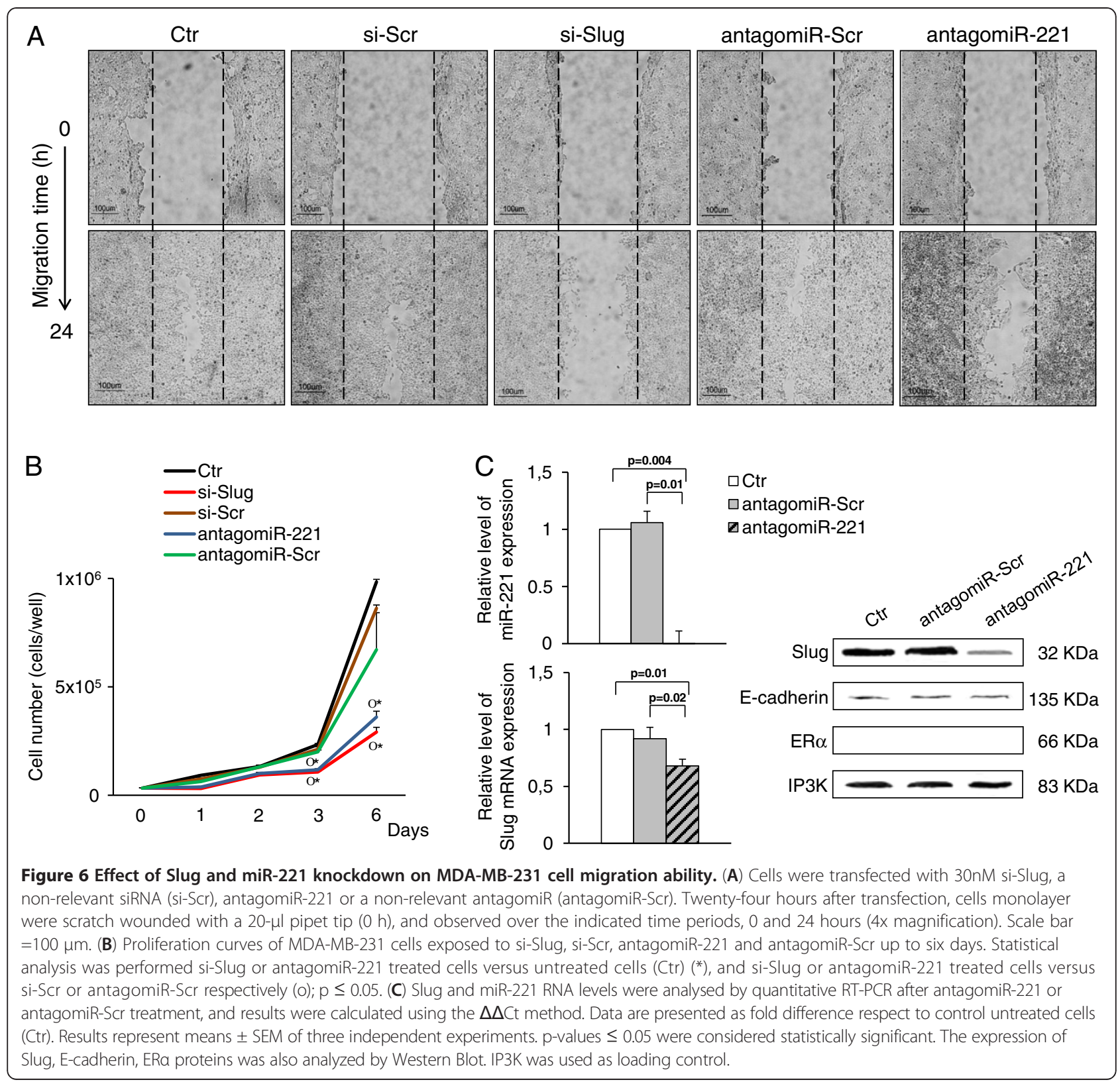


up-regulation of E-cadherin, ER $\alpha$ and TRPS1. No significant difference of gene expression was observed in the cells transfected with a combination of si-Scr and miRScr mimic, in comparison to untreated cells. In addition, the presence of miR-Scr mimic in si-Slug transfected cells did not affect the effect of Slug silencing.

These results suggest that miR-221 down-modulation has not major implications in the phenotype arising from Slug silencing, as ectopic miR-221 expression cannot fully rescue it. In addition, this simultaneous modulation of Slug and miR-221 suggests that silence of Slug could significantly protect cells from progression towards an aggressive phenotype or metastatic stimuli that, in this case, are represented by miR-221 overexpression.

\section{Slug is required for cellular invasion and migration}

To better characterize the correlation between Slug and miR-221 at the functional level, the effects of their knockdown on the invasive potential of MDA-MB-231 cells were evaluated using the scratch-wound healing assay that is usually employed to determine in vitro migratory ability of the cells.

As revealed by a representative scratch assay (Figure 6A), $24 \mathrm{~h}$ after cell monolayers were wounded, control cells (untreated or scrambled cells) had almost completely filled the cleared area. On the contrary, Slug-repressed cells, with a residual amount of miR-221 of approximately $38 \%$, showed strongly impaired cell migration. Therefore, gap closure in Slug repressed cells was significantly reduced because migration from the border of the wound was very slow.

Interestingly, complete knockdown of miR-221 expression by transfection with antagomiR-221, significantly attenuated the gap closing in MDA-MB-231 cells, but not as much as that observed in Slug-repressed cells. These findings confirm the role of miR-221 in the cell invasive potential, and its involvement in promoting the EMT phenotype $[7,8]$, but suggest that the largest contribution to the migratory ability comes from Slug rather than miR-221.

Data from the wound healing assay may in part be explained with the change of cells growth ability, and in part with the change of expression of specific genes. As expected, Slug or miR-221 knocked down cells significantly reduced their proliferation rate compared to control cells (untreated or scrambled cells) (Figure 6B). At the same time, we found that miR-221 knockdown causes a significant but not sufficient decrease of Slug expression (Figure 6C). In fact, residual Slug mRNA (68\%) only slightly decreased the level of Slug protein, and consequently E-cadherin expression was almost unaffected, as revealed by Western blot analysis. This molecular evidence supports the higher ability of miR-221-repressed MDA-MB-231 cells to close the wounded area compared to Slug-silenced cells, strengthening our hypothesis that Slug is indeed linked to cancer cell migration and invasion more than miR-221. In addition, as previously reported [50], we confirm that restoration of ER $\alpha$ could not be achieved by miR-221 knockdown in ER $\alpha$ mRNA-negative cell lines such as MDA-MB-231 (Figure 6C), supporting the notion that ER $\alpha$ is a direct target of miR-221 at the translation level.

Furthermore, data from miR-221 knockdown suggest that unlike Slug, probably one of its negative regulators could be a miR-221 target. While further investigations on a possible Slug / miR-221 circuit are needed, our data suggest that Slug is preferable to miR-221 as potential target to obtain inhibition or slowing down of EMT and metastasis.

\section{Conclusions}

Taken together, the results presented here provide for the first time evidence of a correlation between Slug transcription factor and miR-221 in MDA-MB-231 breast cancer cells. However, considering the complexity of EMT phenomenon, further experiments are needed to explore the possible Slug / miR-221 circuit, especially to understand regulatory interactions with potential unknown factors acting as molecular mediators inside the loop. This report suggests that miR-221 is, in part, dependent on Slug in breast cancer cells, and that Slug plays a more important role than miR-221 in cell migration and invasion. Therefore, our evidence may be useful for developing therapeutical approaches for poor prognosis breast cancers.

Competing interests

The authors declare that they have no competing interests.

\section{Authors' contributions}

$\mathrm{RP}$ and $\mathrm{EL}$ organized the study. AL, LP, FV and EL carried out the cell culture and molecular studies, and participated in the data analysis. RG participated in the design and coordination of the study. RP, EL, AL and RG contributed to the interpretation of the results. All authors read and approved the final manuscript. The authors thank dr. Brya Grace Matthews for English language corrections.

\section{Acknowledgements}

This work was supported by the Fondazione Cassa di Risparmio di Padova e Rovigo. E.L. is a recipient of a fellowship from the Fondazione Cassa di Risparmio di Ferrara.

\section{Author details}

${ }^{1}$ Department of Biomedical and Specialty Surgical Sciences, University of Ferrara, Ferrara 44121, Italy. ${ }^{2}$ Department of Life Sciences and Biotechnology, University of Ferrara, Ferrara 44121, Italy.

Received: 14 May 2012 Accepted: 28 September 2012

Published: 2 October 2012

\section{References}

1. Nieto MA: The ins and outs of the epithelial to mesenchymal transition in health and disease. Annu Rev Cell Dev Biol 2011, 27:347-376.

2. Vincent-Salomon A, Thiery JP: Host microenvironment in breast cancer development: epithelial-mesenchymal transition in breast cancer development. Breast Cancer Res 2003, 5(2):101-106. 
3. De Herreros $A G$, Peiró $S$, Nassour M, Savagner $P$ : Snail family regulation and epithelial mesenchymal transitions in breast cancer progression. J Mammary Gland Biol Neoplasia 2010, 15(2):135-147.

4. Barrallo-Gimeno A, Nieto MA: The Snail genes as inducers of cell movement and survival: implications in development and cancer. Development 2005, 132(14):3151-3161.

5. Thiery JP, Acloque H, Huang RYJ, Nieto MA: Epithelial-mesenchymal transitions in development and disease. Cell 2009, 139(5):871-890.

6. Gregory PA, Bracken CP, Bert AG, Goodall GJ: MicroRNAs as regulators of epithelial-mesenchymal transition. Cell Cycle 2008, 7(20):3112-3118.

7. Guttilla IK, Adams BD, White BA: ERa, microRNAs, and the epithelialmesenchymal transition in breast cancer. Trends Endocrinol Metab 2012, 23(2):73-82.

8. Wright JA, Richer JK, Goodall GJ: microRNAs and EMT in mammary cells and breast cancer. J Mammary Gland Biol Neoplasia 2010, 15(2):213-223.

9. Howe EN, Cochrane DR, Richer JK: The miR-200 and miR-221/222 microRNA families: opposing effects on epithelial identity. J Mammary Gland Biol Neoplasia 2012, 17(1):65-77.

10. Burk U, Schubert J, Wellner U, Schmalhofer O, Vincan E, Spaderna S, Brabletz $T$ : A reciprocal repression between ZEB 1 and members of the miR-200 family promotes EMT and invasion in cancer cells. EMBO Rep 2008, 9(6):582-589.

11. Wellner U, Schubert J, Burk UC, Schmalhofer O, Zhu F, Sonntag A, Waldvogel B, Vannier C, Darling D, Zr Hausen A, Brunton VG, Morton J, Sansom O, Schüler J, Stemmler MP, Herzberger C, Hopt U, Keck T, Brabletz S, Brabletz T: The EMT activator ZEB1 promotes tumorigenicity by repressing stemness-inhibiting microRNAs. Nat Cell Biol 2009, 11(12):1487-1495.

12. Reshmi G, Sona C, Pillai MR: Comprehensive patterns in microRNA regulation of transcription factors during tumor metastasis. J Cell Biochem 2011, 112(9):2210-2217.

13. Wang J, Haubrock M, Cao KM, Hua $X$, Zhang CY, Wingender E, Li J: Regulatory coordination of clustered microRNAs based on microRNAtranscription factor regulatory network. BMC Syst Bio/ 2011, 5:199.

14. Moes M, Le Béchec A, Crespo I, Laurini C, Halavatyi A, Vetter G, Del Sol A Friederich E: A novel network integrating a miRNA-203/SNAI1 feedback loop which regulates epithelial to mesenchymal transition. PLoS One 2012, 7(4):e35440.

15. Liu YN, Yin JJ, Abou-Kheir W, Hynes PG, Casey OM, Fang L, Yi M, Stephens RM, Seng V, Sheppard-Tillman H, Martin P, Kelly K: MiR-1 and miR-200 inhibit EMT via slug-dependent and tumorigenesis via slug-independent mechanisms. Oncogene 2012, doi:10.1038/onc.2012.58. in press.

16. Kim T, Veronese A, Pichiorri F, Lee TJ, Jeon YJ, Volinia S, Pineau P, Marchio A, Palatini J, Suh SS, Alder H, Liu CG, Dejean A, Croce CM: p53 regulates epithelial-mesenchymal transition through microRNAs targeting ZEB1 and ZEB2. J Exp Med 2011, 208(5):875-883.

17. Stinson S, Lackner MR, Adai AT, Yu N, Kim HJ, O'Brien C, Spoerke J, Jhunjhunwala S, Boyd Z, Januario T, Newman RJ, Yue P, Bourgon R, Modrusan Z, Stern HM, Warming S, de Sauvage FJ, Amler L, Yeh RF, Dornan D: TRPS1 targeting by miR-221/222 promotes the epithelial-tomesenchymal transition in breast cancer. Sci Signal 2011, 4(177):ra41.

18. Kim NH, Kim HS, Li XY, Lee I, Choi HS, Kang SE, Cha SY, Ryu JK, Yoon D, Fearon ER, Rowe RG, Lee S, Maher CA, Weiss SJ, Yook JI: A p53/miRNA-34 axis regulates Snail1-dependent cancer cell epithelial-mesenchymal transition. J Cell Biol 2011, 195(3):417-433.

19. Bracken CP, Gregory PA, Kolesnikoff N, Bert AG, Wang J, Shannon MF, Goodall GJ: A double-negative feedback loop between ZEB1-SIP1 and the microRNA-200 family regulates epithelial-mesenchymal transition. Cancer Res 2008, 68(19):7846-7854.

20. Shah MY, Calin GA: MicroRNAs miR-221 and miR-222: a new level of regulation in aggressive breast cancer. Genome Med 2011, 3(8):56.

21. Mancini M, Petta S, lacobucci I, Salvestrini V, Barbieri E, Santucci MA: Zinc finger transcription factor slug contributes tothe survival advantage of chronic myeloid leukemia cells. Cell Signal 2010, 22(8):1247-1253.

22. Guo Y, Zi X, Koontz Z, Kim A, Xie J, Gorlick R, Holcombe RF, Hoang BH: Blocking Wnt/LRP5 signaling by a soluble receptor modulates the epithelial to mesenchymal transition and suppresses met and metalloproteinases in osteosarcoma Saos-2 cells. J Orthop Res 2007, 25(7):964-971

23. Jethwa P, Naqvi M, Hardy RG, Hotchin NA, Roberts S, Spychal R, Tselepis C: Overexpression of Slug is associated with malignant progression of esophageal adenocarcinoma. World J Gastroenterol 2008, 14(7):1044-1052.
24. Côme C, Magnino F, Bibeau F, De Santa Barbara P, Becker KF, Theillet C, Savagner P: Snail and slug play distinct roles during breast carcinoma progression. Clin Cancer Res 2006, 12(18):5395-5402.

25. Vitali R, Mancini C, Cesi V, Tanno B, Mancuso M, Bossi G, Zhang Y, Martinez RV, Calabretta B, Dominici C, Raschellà G: Slug (SNAI2) down-regulation by RNA interference facilitates apoptosis and inhibits invasivegrowth in neuroblastoma preclinical models. Clin Cancer Res 2008, 14(14):4622-4630.

26. Howard EW, Camm KD, Wong YC, Wang XH: E-cadherin upregulation as a therapeutic goal in cancer treatment. Mini Rev Med Chem 2008, 8(5):496-518.

27. Mimeault M, Batra SK: Functions of tumorigenic and migrating cancer progenitor cells in cancer progression and metastasis and their therapeutic implications. Cancer Metastasis Rev 2007, 26(1):203-214.

28. Hotz B, Arndt M, Dullat S, Bhargava S, Buhr HJ, Hotz HG: Epithelial to mesenchymal transition: expression of the regulators snail, slug, and twist in pancreatic cancer. Clin Cancer Res 2007, 13(16):4769-4776.

29. Galardi S, Mercatelli N, Giorda E, Massalini S, Frajese GV, Ciafrè SA, Farace MG: miR-221 and miR-222 expression affects the proliferation potential of human prostate carcinoma cell lines by targeting p27Kip1. J Biol Chem 2007, 282(32):23716-23724.

30. Pineau P, Volinia S, McJunkin K, Marchio A, Battiston C, Terris B, Mazzaferro $V$, Lowe SW, Croce CM, Dejean A: miR-221 overexpression contributes to liver tumorigenesis. Proc Natl Acad Sci USA 2010, 107(1):264-269.

31. Felicetti F, Errico MC, Bottero L, Segnalini P, Stoppacciaro A, Biffoni M, Felli N, Mattia G, Petrini M, Colombo MP, Peschle C, Carè A: The promyelocytic leukemia zinc finger-microRNA-221/-222 pathway controls melanoma progression through multiple oncogenic mechanisms. Cancer Res 2008, 68(8):2745-2754.

32. Di Leva G, Gasparini P, Piovan C, Ngankeu A, Garofalo M, Taccioli C, lorio MV, Li M, Volinia S, Alder H, Nakamura T, Nuovo G, Liu Y, Nephew KP, Croce CM: MicroRNA cluster 221-222 and estrogen receptor alpha interactions in breast cancer. J Nat/ Cancer Inst 2010, 102(10):706-721.

33. Rao X, Di Leva G, Li M, Fang F, Devlin C, Hartman-Frey C, Burow ME, Ivan M, Croce CM, Nephew KP: MicroRNA221/222 confers breast cancer fulvestrant resistance by regulating multiple signaling pathways. Oncogene 2011, 30(9):1082-1097.

34. Zhao R, Wu J, Jia W, Gong C, Yu F, Ren Z, Chen K, He J, Su F: Plasma miR221 as a predictive biomarker for chemoresistance in breast cancer patients who previously received neoadjuvant chemotherapy. Onkologie 2011, 34(12):675-680.

35. Ye Y, Xiao Y, Wang W, Yearsley K, Gao JX, Barsky SH: ERalpha suppresses slug expression directly by transcriptional repression. Biochem J 2008, 416(2):179-187.

36. Ye Y, Xiao Y, Wang W, Yearsley K, Gao JX, Shetuni B, Barsky SH: ERalpha signaling through slug regulates E-cadherin and EMT. Oncogene 2010, 29(10):1451-1462.

37. Dhasarathy A, Kajita M, Wade PA: The transcription factor snail mediates epithelial to mesenchymal transitions by repression of estrogen receptor-alpha. Mol Endocrinol 2007, 21(12):2907-2918.

38. Torreggiani E, Lisignoli G, Manferdini C, Lambertini E, Penolazzi L, Vecchiatini R, Gabusi E, Chieco P, Facchini A, Gambari R, Piva R: Role of Slug transcription factor in human mesenchymal stem cells. J Cell Mol Med 2012, 16(4):740-751.

39. Lambertini E, Lisignoli G, Torreggiani E, Manferdini C, Gabusi E, Franceschetti T, Penolazzi L, Gambari R, Facchini A, Piva R: Slug gene expression supports human osteoblast maturation. Cell Mol Life Sci 2009, 66(22):3641-3653

40. Penolazzi L, Tavanti E, Vecchiatini R, Lambertini E, Vesce F, Gambari R, Mazzitelli S, Mancuso F, Luca G, Nastruzzi C, Piva R: Encapsulation of mesenchymal stem cells from Wharton's jelly in alginate microbeads. Tissue Eng Part C Methods 2010, 16(1):141-155.

41. Chen Y, Gelfond J, McManus LM, Shireman PK: Temporal microRNA expression during in vitro myogenic progenitor cell proliferation and differentiation: regulation of proliferation by miR-682. Physiol Genomics 2011, 43(10):621-630.

42. Ciaudo C, Servant N, Cognat V, Sarazin A, Kieffer E, Viville S, Colot V, Barillot E, Heard E, Voinnet $O$ : Highly dynamic and sex-specific expression of microRNAs during early ES cell differentiation. PLoS Genet 2009, 5(8):e1000620.

43. Cailleau R, Olivé M, Cruciger QV: Long-term human breast carcinoma cell lines of metastatic origin: preliminary characterization. In Vitro 1978, 14(11):911-915. 
44. Yang X, Welch DR, Phillips KK, Weissman BE, Wei LL: KAl1, a putative marker for metastatic potential in human breast cancer. Cancer Lett 1997, 119(2):149-155.

45. Baranwal S, Alahari SK: Molecular mechanisms controlling E-cadherin expression in breast cancer. Biochem Biophys Res Commun 2009, 384(1):6-11.

46. Kajita M, McClinic KN, Wade PA: Aberrant expression of the transcription factors snail and slug alters the response to genotoxic stress. Mol Cell Biol 2004, 24(17):7559-7566.

47. Vuoriluoto K, Haugen H, Kiviluoto S, Mpindi JP, Nevo J, Gjerdrum C, Tiron C, Lorens JB, Ivaska J: Vimentin regulates EMT induction by Slug and oncogenic $\mathrm{H}$-Ras and migration by governing $\mathrm{Axl}$ expression in breast cancer. Oncogene 2011, 30(12):1436-1448.

48. Hajra KM, Chen DY, Fearon ER: The SLUG zinc-finger protein represses E-cadherin in breast cancer. Cancer Res 2002, 62(6):1613-1618.

49. Sakai D, Suzuki T, Osumi N, Wakamatsu Y: Cooperative action of Sox9, Snail2 and PKA signaling in early neural crest development. Development 2006, 133(7):1323-1333.

50. Zhao J, Lin J, Yang H, Kong W, He L, Ma X, Coppola D, Cheng JQ: MicroRNA-221/222 negatively regulates estrogen receptor alpha and is associated with tamoxifen resistance in breast cancer. J Biol Chem 2008, 283(45):31079-31086.

\section{doi:10.1186/1471-2407-12-445}

Cite this article as: Lambertini et al: Correlation between Slug transcription factor and miR-221 in MDA-MB-231 breast cancer cells. BMC Cancer 2012 12:445.

\section{Submit your next manuscript to BioMed Central and take full advantage of:}

- Convenient online submission

- Thorough peer review

- No space constraints or color figure charges

- Immediate publication on acceptance

- Inclusion in PubMed, CAS, Scopus and Google Scholar

- Research which is freely available for redistribution 